\title{
Study for Assessing the Advancement of Imaging Techniques in Chest Radiographic Images
}

\author{
Savitha S.K. \\ Research Scholar \\ Visvesvaraya Technological University, Belgaum
}

\author{
N.C. Naveen \\ Professor \& HoD \\ Department of Information Science \\ Dayanand Sagar College \& Engineering, Bangalore
}

\begin{abstract}
With the advancement of medical image processing along with computer-aided diagnosis approach, the existing healthcare system is equipped with potential imaging devices (e.g. CT scan, MRI, PET scan etc) that assist precise diagnosis of disease. Although, there is an availability of sophisticated radiological equipments, but sometimes identification of the disease becomes the most challenging task for the physician. This paper discusses mainly about the chest radiographic images and its associated problems that still remain as an open problem in research community. Chest radiographs are normally subjected for preprocessing, feature extraction, and then followed by classification. The paper discusses about the existing research technique for the detection and classification of the disease/abnormalities in chest radiographs. Finally a research gap is explored after reviewing the existing literatures.
\end{abstract}

\section{Keywords}

Chest X-Ray, Chest Radiograph, CT scan, MRI, Medical Image Processing, Tuberculosis, Lung Cancer

\section{INTRODUCTION}

With the advancement of medical image processing, the modern healthcare system has started adopting upcoming technologies in order to give better quality of diagnosis of disease. This paper is more particular about the chest radiograph from various other types of radiological study available in image processing [1]. The process of medical imaging for chest radiographs is also highly dependent on the pre-defined data e.g. clinical history of the patient, allergies, critical illness, etc. Chest radiograph is used for two purposes e.g. i) before treatment-for diagnosis of the disease for the first time and ii) after treatmentfor monitoring the level of effectiveness of the prescribed treatment on the patient e.g. surgery, chemotherapy, medicine, etc[2]. Various diseases that are evaluated using chest radiographs are pneumonia, nodule developments, tuberculosis, lung fibrosis, internal hemorrhage within the chest wall etc [3]. In a nutshell, the chest-radiographs are more concern about the taking the image of the chest pertaining to some chest-related disease or any other abnormalities. However, it is finally the radiologist who writes the summarized report of chest radiographs pertaining to the disease criticality. Hence, the process of disease diagnosis is still dependent on human intervention, which means the summary of chest radiographs depends on skills and expertism of the radiologist or the attending physician for the patient.

It is quite common that in present system, a radiological department in a hospital for a medium size healthcare facility performs scanning of minimum of 100-1000 numbers of patients on a daily basis. Hence, it is the most challenging part of the job of radiologist to manually go through each and every chest radiographs and generates inference of the clinical report. Hence, there is a need of an automated system that can make the inferences of the radiological reports using the potential charecteristics of an image processing. Another bigger problem is the outcome of the detection is applicable for treatable diseases like pneumonia or tuberculosis, but it is not at all enough for critical and fatal disease like cancer. A cancer has various stages that are purely based on symptoms in the progression of the disease [4]. Hence, a software application is highly demanded that can diagnose the radiographic image of the cancer and can determine the stages of the cancer. This process is also called as classification of disease from radiographic images.

Studies in this direction have already begun from the year 2000, where various researchers have introduced various techniques to perform detection of the disease. The existing work has witnessed various techniques for detection as well as classification of the disease. At present the detection of abnormalities or disease has the challenging problem of segmentation, where the majority of the studies have been already concentrated on. The segmentation process solves the proper identification of rib cages that is highly essential in diagnosis. Various researchers have adopted neural network, genetic algorithm, support vector machine, etc for carrying out classification (or prediction) of the specific stages of the disease from the chest radiographs. However, all such techniques are still the closed doors of research and couldn't still make out in the hospitals. Hence, this paper has aimed to understand the modern system of performing chest radiography. It also aims to understand the progress being made in the research community of medical image processing pertaining to abnormality or disease detection and classification process for chest radiographs. Section 2 discusses about the advanced diagnostic imaging technologies followed by discussion of techniques of disease detection from chest radiographs in Section 3. Discussion towards existing segmentation techniques is carried out in Section 4. Section 5 discusses about the existing techniques of classification of the stages of disease from chest radiographs followed by discussion of existing survey studies. Section 7 discusses very briefly about the database frequently used in the study and finally summarization of the study is jotted in Section 8.

\subsection{Background}

In the area of radiological for medical sector, various sophisticated equipments have been evolved leading to the commercial practices of using such devices in order to diagnose the diseases properly and visualize the clinical importance of the area of diagnosis. At present, various diseases pertaining to the lungs are normally diagnosed using chest radiographs. Not 
only, it is one of the ongoing conventional mechanisms to diagnose the chest related diseases preferred by physician, but also the outcomes are quite reliable in nature. Although, usage of chest radiographs are associated with clinical advantages, but it has its limitations too that sometimes acts as a hindrance to the accurate diagnosis of the critical illness condition. Digital Chest $\mathrm{x}$-ray is the most frequently adopted imaging technology that leads faster result generation and is also cost effective. However, it is also associated with issues of over-projection because of which some portion of the targeted area cannot be visualized properly. Such issues can be solved using more advanced imaging techniques e.g. CT scan or MRI. The acquisition of the chest radiographs are obtained from the front and lateral views of the patient in standing position. There is also availability of portable devices that can perform chest radiography for the bed-ridden patients. CT-scan and MRI is also taken by the patient in supine position. Various critical conditions e.g. formation of nodules, tuberculosis, fibrosis of lungs can be diagnosed using chest radiographs. A sample chest radiograph is shown in Fig.1, where a small nodule is seen in left lung.

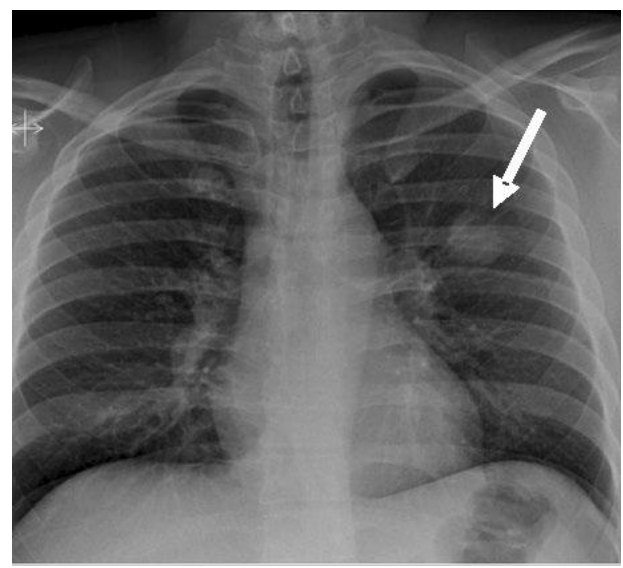

Fig 1: Sample Chest Radiograph

At present, digital techniques has substituted the analogue techniques for performing radiological imaging process. There are several advantages of adoption of the digital imaging process as it offers higher dimensionality of analysis if the image acquisition is done in preferred manner. With the advancement of the data analytics, it is now very much possible to perform advance analysis over the chest radiographs and explore more latent facts about the chest related disease. The frequently used digital imaging technologies for human anatomy at current age are briefly discussed as follows:

\subsubsection{Ultrasound}

This technique uses high frequency sound waves on the targeted area to perform disease detection. Although, it is normally used in stages of semester monitoring during pregnancy, but it is also frequently adopted for lung disease detection e.g. pleural effusions and level of drainage of it. Various sorts of biopsies as well as pneumonia condition can be easily detected by using ultrasound. However, it can be only used for lower level of diagnosis and cannot be used to diagnose critical abnormalities.

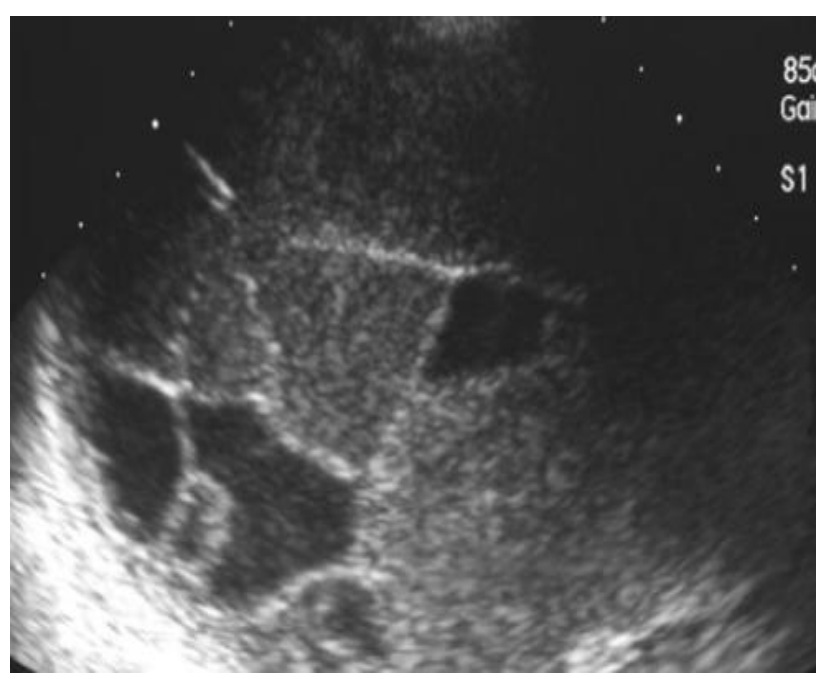

Fig 2: Ultrasound of the Chest

\subsubsection{Computed Tomography}

It is another frequently used imaging technique for screening human organs. It deploys $\mathrm{x}$-chest on the targeted portion of chest for obtaining a detailed image of it. Owing to highly controlled usage of x-rays, CT scans doesn't results in overprojections. Any abnormalities e.g. nodule or lesion of extremely smaller size can be identified in the CT generated images. CT scan can be configured for both high resolution as well as multi-detection in images. A high resolution of CT scan image assist to visualize the abnormalities / disease more clearly and multi-detection approach assist to generate a threedimensional view leading to more in-depth clinical investigation of abnormalities / disease in chest. Fig. 3 shows a sample CT scan image. Fig.3 (a) is the normal CT scan image, Fig.3(b) is high resolution CT scan image, while Fig.3(c) is one of the view of $3 \mathrm{D}$ from multi-detection approach in CT imaging. The type of the radiation used by the CT scan is highly hazardous for health and poses big limitations for persistent usage in diagnosis.

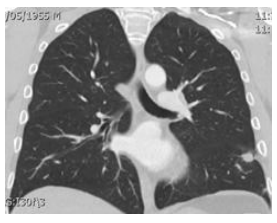

(a)

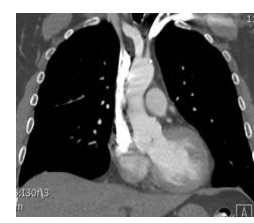

(b)

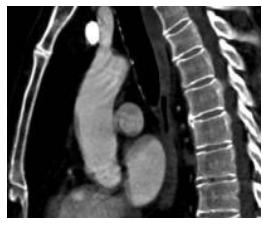

(c)
Fig 3: CT Image of the Chest

\subsubsection{Positron Emission Tomography}

This process is just like a normal CT scan; however, the difference is the patient is injected with radioactive tracers before performing PET scan, which is not seen in CT scan process. The tracer assist to show the exact position of the abnormalities by displaying a specific color pattern only recognized by the image acquisition and analysis machine of PET scan. Normally, it is used in oncology. However, PET scan suffers from the problem of precise identification of nodules or lesions of very smaller size $(<5 \mathrm{~mm})$. Therefore, at present both PET and CT scan are performed together to increase the potential of disease diagnosis. The critical problem of the usage of the PET scan is that radiological chemicals are injected to the patient, which is always a risk factor. The usage of the PET/CT scan is frequently used in the diagnosis of the 
ontological diseases mainly. Fig.4 shows the sample PET/CT scan images. Fig.4 (a) shows the CT imaging highlighting the localization of nodule within a lung. Fig.4 (b) shows the hotspot area from the position emission showing the position of the disease, while Fig.4(c) shows the extent of metastasis within the lung region.

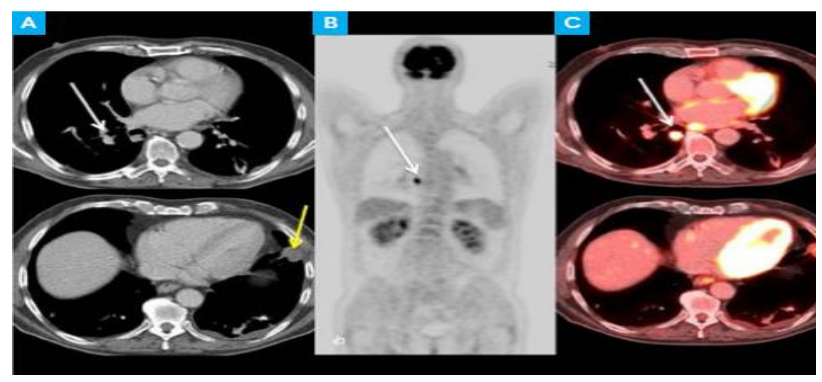

Fig 4: PET/CT Image of the Chest

\subsubsection{Magnetic Resonance Imaging}

This technique harnesses the resonance signal generated from proton of an organic matter when such matters are subjected to the potential magnetic field. Such resonant signals are normally excited by the specific pulses of the radio frequency. MRI assists in generation of superior quality of radiological images for neuro-imaging, cardiovascular study, musculo-skeleton, Functional MRI etc. One of the greatest advantages of using MRI is its zero exposure of risk as it doesn't involve any lethal radiation that can be found in other radiological processes. Fig.5 shows the MRI of a chest wall exhibiting a bigger size nodule inside the ribcage of lung.

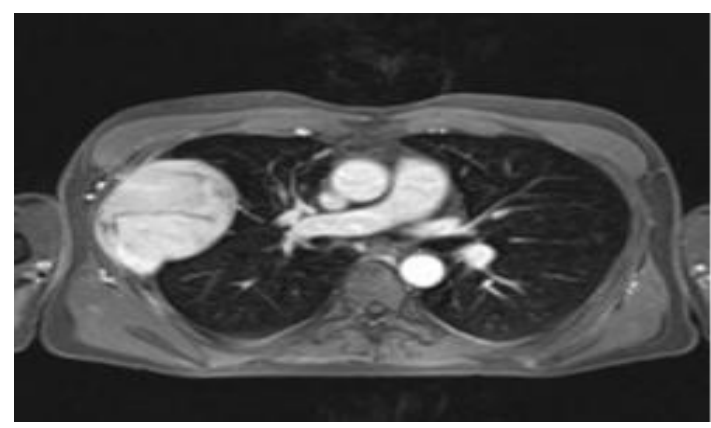

Fig 5: MRI Image of the Chest

\subsection{The Problem}

The usage of chest radiographic images is mainly meant for detection of any abnormalities as well as any significant disease in the patient. The previous section has discussed about the advancement of the digital imaging technology available at present era for diagnosis the chest diseases. However, from research viewpoint, the study has begun for this issue somewhere on 90s. This section will therefore elaborate the conventional techniques explored in disease detection from the chest radiographic images.
One of the standard research works is found to be carried out by Ginneken et al. [5] in 2002. Till date the study is also found cited by more than 150 researchers worldwide. The study has presented an automated technique to explore the abnormal area of chest image. Considering the case study of tuberculosis, the technique has implemented a unique segmentation process followed by feature (texture) extraction process. The authors have carried out statistical analysis over feature vector classification process in order to understand the outcome effectiveness. Different from conventional technique, Fanzou et al. [6] have introduced a concept of Content-Based Image Retrieval (commonly known as CBIR) process considering the case study of lung cancer. The author has adopted XML to store the image and used MPEG-7 descriptors [7] to extract features. The outcome of the study is basically the most relevant image extracted from the dataset against the response of query (untrained) image. The outcome of the system has been experimented with various available applications for image retrieval with respect to precision.

Adoption of Computer-Aided Diagnosis (CAD) was emphasized by Le [8]. However, the study provides some unique approach by highlighting that healthcare database system acts as a bridge between user interface and clinical repositories in e-health management system. The authors have also highlighted about i) early nodule detection algorithm, ii) thoracic diameter measurement algorithm, iii) lung boundary detection algorithm, mainly. Study on similar direction was also witnessed in the work of Sharma and Jindal [9], where the authors have initially used region of interest approach of the chest image followed by segmentation of the particular area. The segmented image is than analyzed and subjected to diagnostic indicators. The preprocessing was carried out using Weiner Filter while feature vectors were considered for calcified part, region of interest, size, shape, and contrast etc. Lee et al. [10] have presented a technique to remove the adverse effect of shadows of rib generated in chest radiographs. This study uses region of interest along with active shape model. The contribution of the study is three-folds e.g. i) identifying the exact area of lung from an image, ii) performing segmentation of rib using Generalized Hough Transform (GHT), iii) estimating the image intensity of the ribs using Genetic Algorithm, and iv) perform suppression of it. Tarambale and Lingayat [11][12] have highly signified about the CAD applications in chest radiographs. The authors have introduced a technique that assists in detection of malignant or benign tumors using statistical approach. The outcome of the study was tested using statistical parameters such as standard deviation, mean, entropy, and variance, which is highly, cost effective approach as compared to other techniques.

Same authors have also extended their study on investigating techniques associated with spatial domain [13]. The technique is showcased in Fig.6 and the reason for it is that majority of the existing researchers working on segmentation methods have more or less the similar cadre of approach as shown below. 


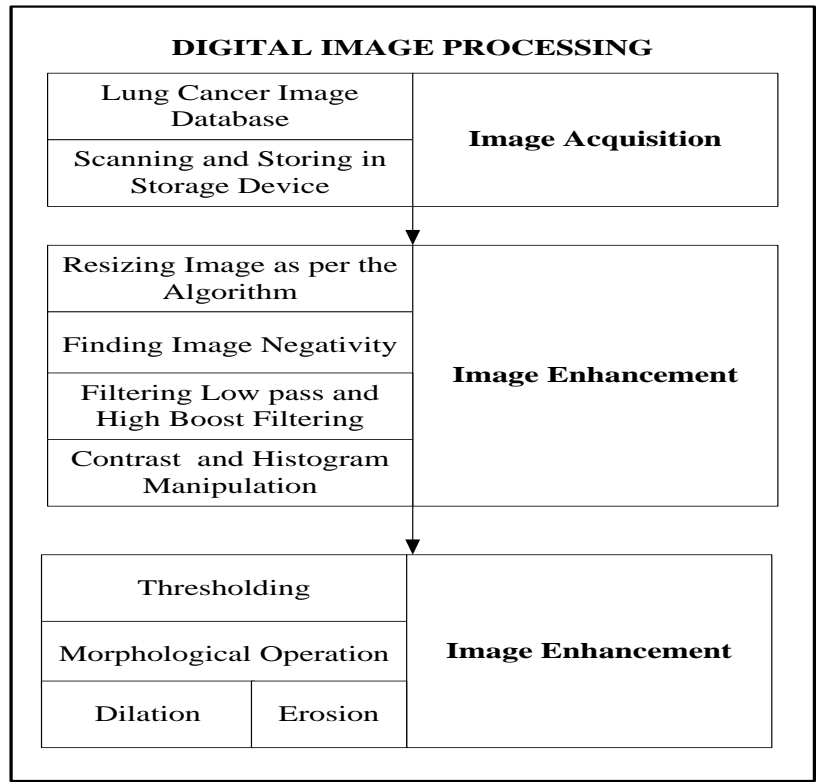

Fig 6: Schema of Technique discussed in [13]
Adoption of both Computer-aided detection as well as diagnosis of another critical chest disease like tuberculosis was done by Leibstein and Nel [14]. The authors have hypothesized that soft tissues surround the lung area could be possibly isolated using high pass filter of Fast Fourier Transform as well as a precise thresholded frequency. Morphological operations like dilation and erosion are applied and followed by that thresholding are specified to extract portion of the lung area which is susceptible for tuberculosis detections. The study conducted by Belhaouair and Kuleev [15] have used spot features in order to identify the disease criticality from the chest radiographs. The authors have presented a mathematical model using homogenous random field as technique of object recognition process. The process calls for applying segmentation by both mode method and spot feature method in order to find the portion of clinical interest in the chest radiographs. Antani [16] have carried out an experiment on chest radiographs for automatic detection of the diseases e.g. tuberculosis. The process consists of localizing the region of the lung followed by sophisticated feature extraction using CBIR process. Using massive datasets, the outcome of the study was evaluated using true and false positives over ROC curves. An extensive study was also carried out by the author by introducing mitigation technique for rotated or skewed image Classification of the lung cancer with and without segmentation is also carried out in this study.

Table 1: Summary of Existing Studies in Disease Detection from Chest Radiographic Images

\begin{tabular}{|c|c|c|c|}
\hline Author & Technique & Study Outcome & Limitation \\
\hline $\begin{array}{l}\text { Ginneken et } \\
\text { al. [5] }\end{array}$ & $\begin{array}{l}\text { Technique: Segmentation, feature } \\
\text { extraction of texture } \\
\text { Dataset: TB Database }\end{array}$ & $\begin{array}{l}\text { Performance } \\
\text { Parameter: True and } \\
\text { False Positive from ROC } \\
\text { curve }\end{array}$ & $\begin{array}{l}\text {-No Comparative Analysis } \\
\text {-No Complexity Analysis }\end{array}$ \\
\hline $\begin{array}{l}\text { Fanzou et } \\
\text { al. [6] }\end{array}$ & $\begin{array}{l}\text { Technique: } \text { CBIR } \\
\text { Dataset: Canadian Lung } \\
\text { Association }\end{array}$ & $\begin{array}{l}\text { Performance } \\
\text { Parameter: Precision }\end{array}$ & $\begin{array}{l}\text {-Unreliable for complex db with noise, } \\
\text { orientation, skew etc. } \\
\text {-Success depends on database design } \\
\text {-increased computation time with } \\
\text { increase in queried image } \\
\text {-probability of stale database is more }\end{array}$ \\
\hline $\begin{array}{l}\text { Sharma and } \\
\text { Jindal [9] }\end{array}$ & $\begin{array}{l}\text { Technique: Bit plane slicing } \\
\text { Database: NIH/NCI Lung Image } \\
\text { Database }\end{array}$ & $\begin{array}{l}\text { Performance } \\
\text { Parameter: Sensitivity, } \\
\text { False positive, accuracy }\end{array}$ & $\begin{array}{l}\text {-No Comparative Analysis } \\
\text {-No Complexity Analysis }\end{array}$ \\
\hline $\begin{array}{lll}\text { Lee et al. } \\
{[10]}\end{array}$ & $\begin{array}{l}\text { Technique: Generalized Hough } \\
\text { Transform, Genetic Algorithm } \\
\text { Database: Not disclosed }\end{array}$ & $\begin{array}{l}\text { Performance } \\
\text { Parameter: } \\
\text { Disclosed }\end{array}$ & $\begin{array}{l}\text {-It is not automated. } \\
\text {-The technique cannot be optimized } \\
\text { owing to its dependency on fitness } \\
\text { function. }\end{array}$ \\
\hline $\begin{array}{l}\text { Tarambale } \\
{[11][12]}\end{array}$ & $\begin{array}{l}\text { Technique: Statistical } \\
\text { Database: JSRT Database }\end{array}$ & $\begin{array}{l}\text { Performance } \\
\text { Parameter: standard } \\
\text { deviation, mean, entropy, } \\
\text { and variance }\end{array}$ & -No Comparative Analysis discussed \\
\hline $\begin{array}{l}\text { Tarambale } \\
{[13]}\end{array}$ & $\begin{array}{l}\text { Technique: Segmentation, } \\
\text { morphological operation. } \\
\text { Database: Not disclosed }\end{array}$ & $\begin{array}{l}\text { Performance } \\
\text { Parameter: Histogram }\end{array}$ & $\begin{array}{l}\text {-Not applicable for sophisticated chest } \\
\text { images } \\
\text {-No Comparative Analysis discussed }\end{array}$ \\
\hline $\begin{array}{l}\text { Leibstein } \\
\text { and Nel } \\
{[14]}\end{array}$ & 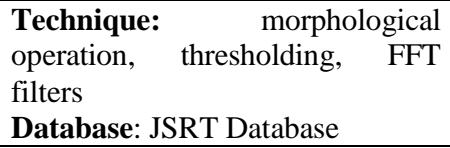 & $\begin{array}{l}\text { Performance } \\
\text { Parameter: Maximum } \\
\text { Height and Width of lung }\end{array}$ & $\begin{array}{l}\text {-Accuracy of detection highly depends } \\
\text { upon preprocessing. } \\
\text {-No benchmarking }\end{array}$ \\
\hline $\begin{array}{l}\text { Belhaouair } \\
\text { and Kuleev } \\
\text { [15] }\end{array}$ & $\begin{array}{l}\text { Technique: Spot feature analysis } \\
\text { Database: Not Disclosed }\end{array}$ & $\begin{array}{l}\text { Performance } \\
\text { Parameter: } \\
\text { Disclosed } \\
\end{array}$ & -Results not discussed \\
\hline Antani [16] & $\begin{array}{l}\text { Technique: Correcting Image } \\
\text { rotation, CBIR, object detection, } \\
\text { feature extraction, SIFT flow } \\
\text { algorithm, } \\
\text { Database: JSRT, Montgomery, } \\
\text { Shenzhen, Indiana, India. }\end{array}$ & $\begin{array}{l}\text { Performance } \\
\text { Parameter: True and } \\
\text { False Positive }\end{array}$ & $\begin{array}{l}\text {-The focus of the paper is too broad. } \\
\text {-Exact algorithms not disclosed. } \\
\text {-No discussion of system performance } \\
\text { or computational complexity. } \\
\text { - No Comparative Analysis discussed }\end{array}$ \\
\hline
\end{tabular}




\subsection{The Proposed System}

Normally the process of image segmentation includes the partitioning of any image in to various set of pixels which are also known as segments. However, it also looks like subtracting background from the foreground of an object, where both the forms of the grounds are defined by the user as well as specific to applications. Segmentation has played one of the major role in analysis of medical images and also in chest radiographs.

Study on segmentation process on chest radiograph dated back in 1995, when Yue et al. [17] have presented a technique of identification of rib edges using segmentation. Till date, the work has been cited by more than 87 researchers in medical image processing. The technique presented by the authors initially identifies the edges of the rib cages for narrowing down the search space of the problem using dynamic programming and curve fitting approach. The features of the chest radiograph images were extracted for both vertical as well as horizontal signatures of the chest radiographs. The edges of the rib cages were then approximated using Hough transformation scheme. The authors have also applied active contour frameworks for edge detection. The study outcome is shown in Fig.7. The visual outcome is much promising as well as comprehensive from the edge detection of the rib cases. This study was also benchmarked by several researchers .This is one of the most standard and effective research attempt towards chest radiographs till date.

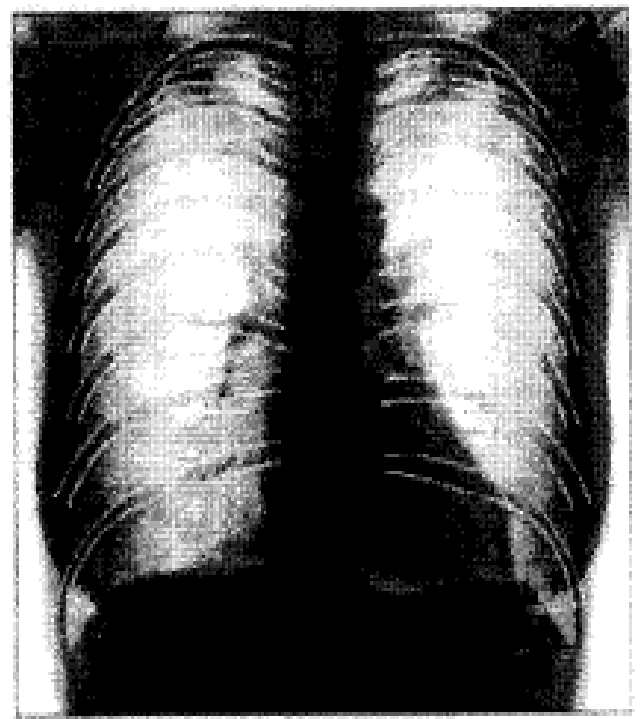

Fig 7: Segmentation results of method described in [17]

Study on similar direction has been carried out by Brown et al. [18] in 1998. The authors have implemented a typical segmentation followed by evaluation of the edges of the lungs in chest radiographs. The technique initially selects the anatomical structures of the chest radiographs and then extracts the significant features followed by grouping of anatomical structures for the purpose of identification. The authors have designed a condition for unidentified anatomical structures. Finally, based on the conditions the descriptions of the symbolic features are extracted and finally the system generates the significant report on abnormalities. Fig. 8 shows the technique adopted by the Brown et al. [18].

A very unique form of the study was introduced by Iakovidis and Papamichalis [19], who have implemented Bezier interpolation technique. This method was designed on java platform and the performance of technique was evaluated by using accuracy, sensitivity and specificity.

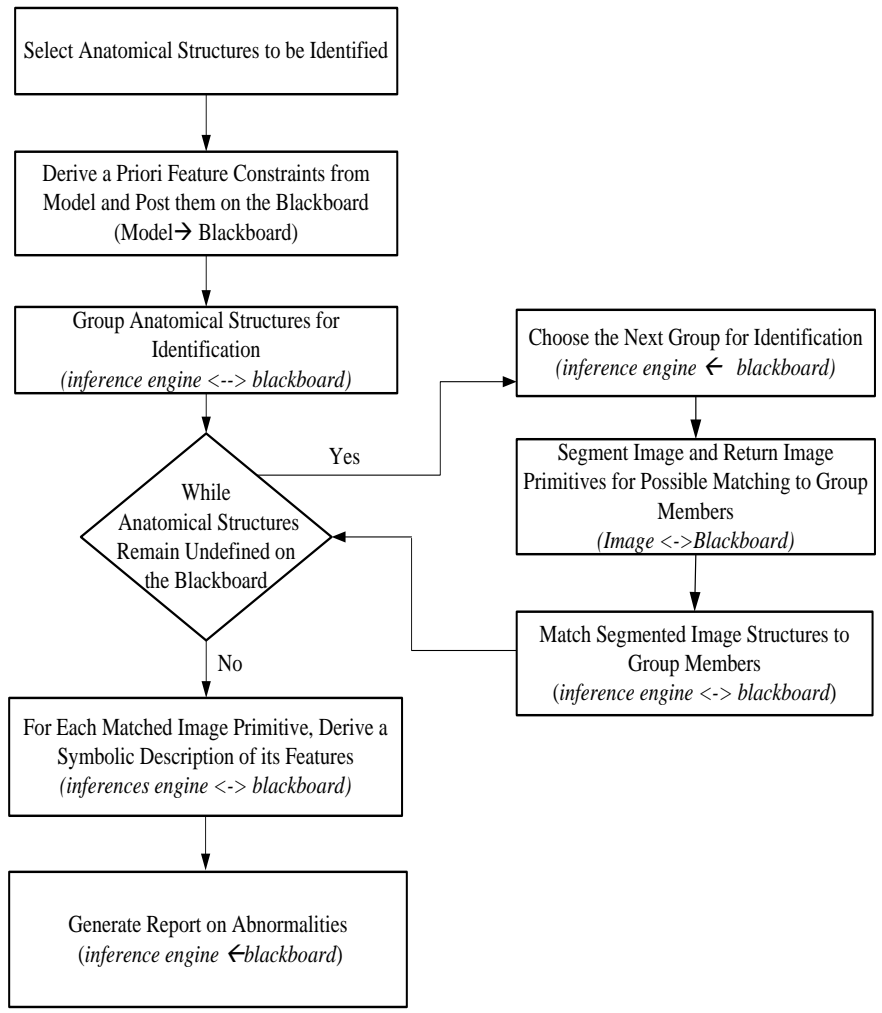

Fig 8: Step-by-step description of method presented in [18]

Another significant study was introduced by Hassen et al. [20], where the authors have implemented the concept of Fuzzy logic as well as concept of morphological operations. The uniqueness of the study was found to be integration of spatial relationships with the segmentation of the chest radiographs. Bandyopadhyay [21] have introduced an algorithm for the detection of the edges of the lung. Fig.9 exhibits the outcomes of the technique adopted by the authors. The technique allows the chest radiographs for representing the edges of the lungs (first image in Fig.9). The boundary of the lung is then scanned and consolidation is done (second image in Fig.9). Finally, a curve is drawn in sequential image pixels for outlining the identified borders of the lung.

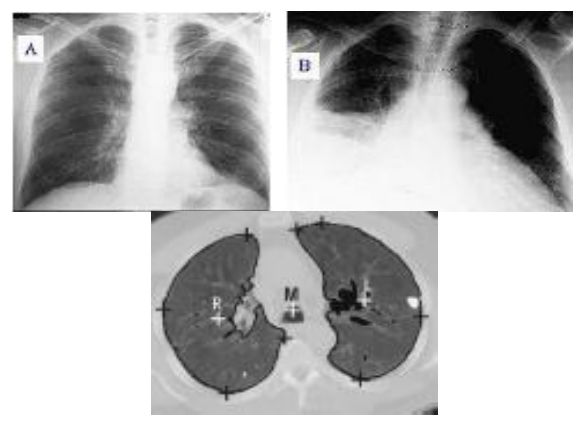

Fig 9: Outcome of Schema presented in [21]

The recent work done by Candemir et al. [22] have carried out the segmentation of the chest radiographs. The direction of the study is towards identifying the edges of the lungs using adaptive approach. The study has also integration of CBIR technique along with shape similarity evaluation with anatomical framework along with better optimization scheme. However, 
conventional methods e.g. SIFT flow technique has been adopted along with graph cut theory, which is quite different in image processing for the purpose of segmentation. The outcome of the study was evaluated using overlapping score with respect to minimum, maximum, and median. Exactly similar work is once recreated by Devi and Viveka [23], which is completely equivalent to work done by Candemir et al. [22]. Ahmad et al. [24] have introduced a unique segmentation process based on the CBIR technique. The uniqueness of this method is implementation of Fuzzy C-Means clustering. The outcome of the study has achieved around $95 \%$ of accuracy, which is the highest till date considering the challenges.

Table 2: Summary of Existing Studies in Segmentation for Chest Radiographic Images

\begin{tabular}{|c|c|c|c|}
\hline Author & Technique & Study Outcome & Limitation \\
\hline Yue et al. [17] & $\begin{array}{l}\text { Technique: Dynamic Programming, } \\
\text { Hough Transforms, curve fitting, } \\
\text { greedy algorithm, active contour } \\
\text { Database: Not Disclosed }\end{array}$ & $\begin{array}{l}\text { Performance Parameter: } \\
\text { mean, standard deviation }\end{array}$ & $\begin{array}{l}\text {-Rib localization process in this is time } \\
\text { consuming }\end{array}$ \\
\hline Brown et al. [18] & $\begin{array}{l}\text { Technique: } \quad \text { Knowledge-based } \\
\text { architecture } \\
\text { Database: St. Vincents Hospital }\end{array}$ & $\begin{array}{l}\text { Performance Parameter: } \\
\text { True positive, False Positive }\end{array}$ & $\begin{array}{l}\text {-Outcomes could be further validated } \\
\text {-Outcomes not found benchmarking }\end{array}$ \\
\hline Iakovidis [19] & $\begin{array}{l}\text { Technique: Bezier Interpolation } \\
\text { Database: No Disclosed }\end{array}$ & $\begin{array}{lr}\text { Performance } & \begin{array}{r}\text { Parameter: } \\
\text { accuracy, }\end{array} \\
\text { specificity } & \end{array}$ & - Outcomes not found benchmarking \\
\hline Hassen et al. [20] & $\begin{array}{llr}\text { Technique: } & \text { Fuzzy } & \text { based } \\
\text { segmentation } & & \\
\text { Database: } & \text { JSRT } & \text { database, } \\
\text { JPCLN001 } & & \end{array}$ & $\begin{array}{l}\text { Performance Parameter: } \\
\text { sensitivity, accuracy, }\end{array}$ & - Outcomes not found benchmarking \\
\hline $\begin{array}{l}\text { Bandyopadhyay } \\
\text { [21] }\end{array}$ & $\begin{array}{l}\text { Technique: Edge detection of the } \\
\text { lung } \\
\text { Database: Not Disclosed }\end{array}$ & $\begin{array}{l}\text { Performance } \quad \text { Parameter: } \\
\text { Not Disclosed }\end{array}$ & $\begin{array}{l}\text { - Outcomes not found benchmarked } \\
\text {-Algorithm complexity not discussed } \\
\text {-Highly dependent on the image contrast. }\end{array}$ \\
\hline $\begin{array}{l}\text { Candemir et al. } \\
{[22]}\end{array}$ & $\begin{array}{l}\text { Technique: Graph cut, SIFT flow, } \\
\text { Database: JSRT database, } \\
\text { Montgomery }\end{array}$ & $\begin{array}{l}\text { Performance Parameter: } \\
\text { Minimum, Maximum, Median }\end{array}$ & $\begin{array}{l}\text {-Outcomes not found benchmarking } \\
\text {-Algorithm complexity not discussed. }\end{array}$ \\
\hline Devi [23] & -Do- & -Do- & -Do- \\
\hline Ahmad et al. [24] & $\begin{array}{l}\text { Technique: Gaussian, FCM, CBIR } \\
\text { Database: JSRT database }\end{array}$ & $\begin{array}{l}\text { Performance Parameter: } \\
\text { execution time, overlap } \\
\text { measure, F-score, precision, } \\
\text { sensitivity, specificity }\end{array}$ & -Nil- \\
\hline
\end{tabular}

\section{EXISTING CLASSIFICATION TECHNIQUES}

The existing techniques of the medical image processing have already assisted in the effective disease diagnosis. The prior section has already witnessed various advanced imaging technologies where detection of lungs diseases are carried out. However, all the techniques discussed in the prior section only identify the diseases, but couldn't make a discrete classification of the disease. Hence, we have identified that there are three classification techniques that are frequently adopted in the existing study.

\subsection{Data Mining Approach}

Basically, the concept of data mining technique calls for analyzing various forms of data and apply processing in order to extract a particular knowledge. The studies conducted by Ada and Kaur et al. [25] have introduced a data mining technique for the classification of the lung cancer. The technique adopted by the author is applying segmentation of lung area followed by feature extraction. However, the study is quite vague as concept of data mining quite differs from the neural network or SVM as they are more inclined towards machine learning process. The real implementation of data mining approach was carried out by Rajan and Prakash [26], where the authors have used cluster analysis on the data. However, significant literatures towards data mining approaches on disease classification on chest radiographs are few to find in literatures.

\subsection{Neural Network}

One of the advantages of adoption of neural network is the minimization of error by its iterative learning process. Hence, if neural network is utilized in classification problem, minimal errors can be expected. Studies towards implementing neural network were seen in the work of Suzuki et al. [27]. The author have adopted CAD scheme along with neural network to achieve a sensitivity of $82 \%$. The study findings have also shown around $68 \%$ of minimization of false positive. Gomathi and Thangaraj [28] have designed a classification technique based on neural network. The outcome shows accomplishment of $79 \%$ of sensitivity and $85 \%$ of specificity as maximum values for test set 
of images. Studies on similar direction has been done by Udeshani et al. [29]

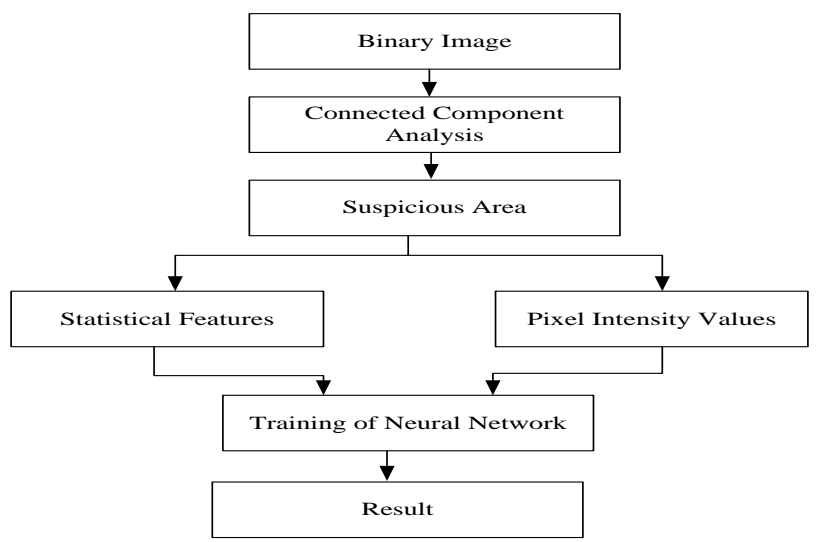

Fig 10: Technique Adopted by Work in [29]

The technique adopted by the author was shown in Fig.10. Median filter was used for preprocessing followed by segmentation on JSRT database. Backpropagation algorithm was implemented to train the images for optimal classification process. Similar category of work was also carried out by Patil and Kuchanur [30]. The uniqueness lies in implementing second order statistical features e.g. contrast, correlation, energy, and homogeneity as the texture features. Karthikeyan et al. [31] as well as Kumar [32] have also used neural network using backpropagation algorithm and feedforward algorithm for carrying out optimal segmentation process of CT images of lung. Adoption of neural network is seen in bit unique style of implementation in the work carried out by Ramalho et al. [33]. The authors have employed contour model for carrying out segmentation of lung, which is then synthesized using spatial interdependence matrix. Finally, neural network was used for classification process. The outcome has accomplished around $96 \%$ of accuracy.

\subsection{Support Vector Machine}

Existing literatures have also witnessed a significant implementation of Support Vector Machines towards classification of diseases or abnormalities in chest radiographs. Support vector machine (SVM) is a type of supervised machine learning technique with a capability to classify both linear and non-linear problems of classification. Teramoto and Fujita [34] have implemented SVM on LIDC database to classify the critical nodules involved in classification process of chest radiographs. Aarthy and Raghupathy [35] have jointly implemented SVM with radial basis function for increasing the accuracy in classification process. The authors have also used wavelet transforms of Multiscale along with morphological operation. The outcome of the study was evaluated using mean, standard deviation, contrast, and entropy.

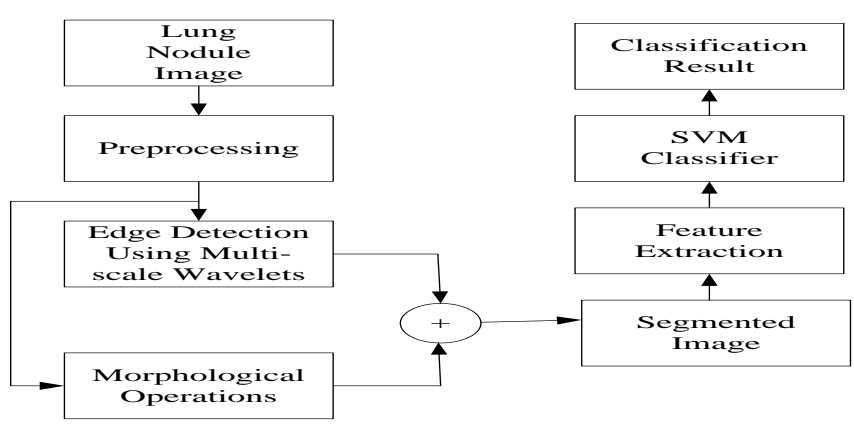

Fig 11: Technique based on SVM [34]

Gomathi and Thangaraj [36] have also used SVM along with design of linear kernel classifier, radial basis classifier, and polynomial kernel classifier for carrying out an effective classification scheme. The outcome of the study was evaluated using sensitivity and specificity. Similar direction of studies using SVM was also seen in the work of Tidke et al. [37] and Sivakumar [38]. Sivakumar [38] have also implemented fuzzy clustering method along with SVM on LIDC database.

Parveen [39] have used the design of gray level co-occurrence matrix for performing extraction of feature using SVM. Similar work is also carried out by Nivetha [40]. Gindi et al. [41] have used both Curvelets and SVM for performing classification of early stages of lung cancer. Kaur and Singh [42] have jointly used both neural network and SVM together. Our prior experiment [43] has also implemented SVM in order to identify the edges of the lungs from the chest radiographs. We have also compared our outcomes with fuzzy approach and fusion intensity based approach to find lower value of contour distance in our study. Wang et al. [44] has discussed about modelling a critical disease using Markov principle and optimization is performed using unsupervised learning technique. Gajdhane and Deshpande [45] have used watershed segmentation process in order to detect the specific stage of the lung cancer. The authors have applied a simple process where the clinical image is initially subjected to pre-processing with segmentation as its last step. The processed image is then subjected to the extraction of features using morphological operations as well as colorimetric approach.

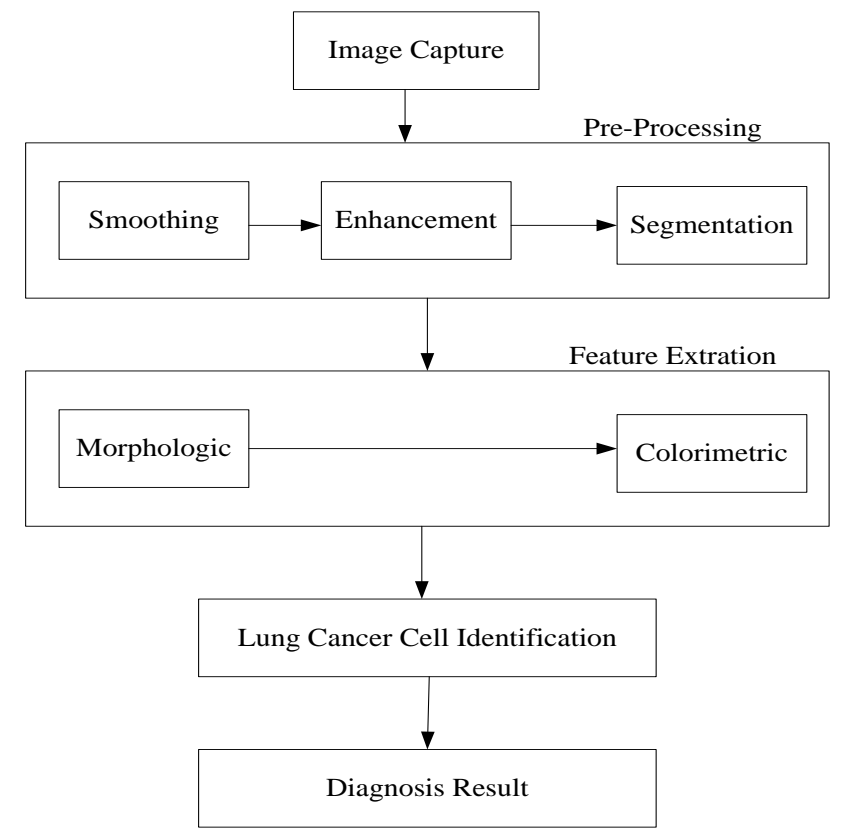

Fig 12: Schema of Technique discussed in [45] 
Fig.12 shows the technique adopted in the work of [45]. The authors have also considered classification using SVM to determine the exact stage of cancer in the form of centimeters measurements of tumor. The authors have also designed conditions of the stages of the cancer e.g.

- $\quad$ Stage-I: Confirmation of site of cancer in chest

- Stage-II: Confirmation of spread of cancer from lung to chest.

- $\quad$ Stage-III: Confirmation of spreading of the disease to other body part.

Vivek and Swathika [46] have presented a technique to address the criticality of problems using multiple classes of SVM. The inclination of the study is basically towards detection of tuberculosis using graph cut technique.

\section{EXISTING SURVEY WORK}

The research work on chest radiography has been witnessed more than a decade ago. The initial review of the techniques towards diagnosis of the disease from the chest-radiograph has been seen in the work of Ginneken et al. [47]. It is one of the most standard surveys conducted on the year 2001 and has around 384 citations from the other reputed researchers till date. The study has signified the importance of Computer-Aided diagnosis of the chest radiographic images by elaborated discussion on conventional enhancement techniques, subtraction techniques, segmentation techniques, study towards detections of the rib cage and various forms of analysis of the chest-images for detection of nodules or susceptible portion of the radiographs. The outcome of the study has discussed some of the solved as well as unsolved problem in processing chest radiographs. Another significant review work towards chest radiographs is also carried out by Vershney [48] in 2002. This review paper is completely focused on discussing about the segmentation techniques on the particular form of the chest radiographs i.e. CT scan images. The authors have discussed about the neural network based techniques, level set methods along with various

Table 3: Summary of existing Reviews towards Chest Radiographs

\begin{tabular}{|c|c|c|c|c|}
\hline \multirow[t]{2}{*}{ Authors-Year } & \multirow[t]{2}{*}{ Focus of paper } & \multirow[t]{2}{*}{ Techniques discussed } & \multicolumn{2}{|c|}{ Study of Reference } \\
\hline & & & $\begin{array}{c}\text { Total } \\
\text { Reference }\end{array}$ & $\begin{array}{c}\text { Relevant } \\
\text { References }\end{array}$ \\
\hline $\begin{array}{lll}\text { Ginneken } & \text { et } & \text { al. } \\
{[47]-2001} & & \end{array}$ & $\begin{array}{l}\text { CAD Techniques for } \\
\text { chest radiographs }\end{array}$ & $\begin{array}{l}\text { i) general processing, ii) Segmentation, } \\
\text { iii) Analysis Techniques, iv) Nodule } \\
\text { Detection, v) Analysis of Texture }\end{array}$ & 200 & 178 \\
\hline $\begin{array}{l}\text { Varshney et al. } \\
{[48]}\end{array}$ & $\begin{array}{l}\text { Segmentation } \\
\text { techniques, CT scan }\end{array}$ & $\begin{array}{l}\text { i) neural networks, ii) model fitting, iii) } \\
\text { data direction method, iv) level set } \\
\text { method, v) Rule-based recognition }\end{array}$ & 26 & 25 \\
\hline $\begin{array}{l}\text { Bodhey \& Sable } \\
{[49]}\end{array}$ & $\begin{array}{l}\text { Segmentation, tumor } \\
\text { identification, chest CT } \\
\text { scan images }\end{array}$ & $\begin{array}{l}\text { i) preprocessing, ii) removing } \\
\text { background, iii) } \\
\text { Segmentation }\end{array}$ & 14 & 9 \\
\hline $\begin{array}{l}\text { Ginneken et al. } \\
{[50]}\end{array}$ & $\begin{array}{ll}\text { Chest } & \text { Radiograph } \\
\text { study } & \end{array}$ & $\begin{array}{l}\text { i) Image normalization, ii) Segmentation, } \\
\text { iii) shape analysis, iv) recess analysis, v) } \\
\text { texture analysis, vi) symmetry analysis }\end{array}$ & 15 & 7 \\
\hline Jaeger et al. [51] & $\begin{array}{l}\text { Automatic diagnosis of } \\
\text { tuberculosis }\end{array}$ & $\begin{array}{l}\text { i) Preprocessing, ii) } \text { Histogram } \\
\text { equalization, iii) Bone Suppression, iv) } \\
\begin{array}{l}\text { Boundary detection, v) Classification } \\
\text { process }\end{array}\end{array}$ & 69 & 45 \\
\hline
\end{tabular}

forms of model fitting techniques and rule-based recognition methods towards processing chest radiographs. Similar direction of the work is also carried out by Bodhey et al. [49] in 2013, where the authors have discussed about the conventional techniques for performing segmentation on CT scan images. After 14 years, the same author Ginneken et al. [50] have once again investigated about the emergence of chest radiographs and this time the focus was strictly to investigate the tuberculosis disease to be diagnosed automatically.

Another significant work that talks about an extended investigation towards chest radiographs pertaining to a specific disease is by Jaeger et al. [51]. The direction of the work is almost similar to Ginneken et al. [50]. In 2014, Ilakkiya et al. [52] have also reviewed various forms of the techniques of the chest radiographs processing for the purpose of precise diagnosis of tuberculosis. Same year, Naing and Htike [53] have also reviewed some of the essential techniques towards automatic detection of the tuberculosis from the chest radiograph images. This paper has discussed about the screen techniques adopted for diagnosis of tuberculosis disease from chest $\mathrm{x}$-ray images. Jeager et al. [54] have published their manuscript for review of automatic techniques of screening in IEEE transactions on the year 2014. The paper has also discussed about the various techniques used for segmentation, feature extractions, classifications, as well as existing implementations of the system. The continuation of the study toward disease identification from chest radiographs was carried out by Balagangadhar and Srilatha [55] in 2015. Similar direction of review work was also presented by Joshi and Nalgirkar [56] where the authors have presented various techniques to carry out segmentation process of the chest radiographs.

Table 3 will highlight the existing significant survey work being carried out on till date. The tabulated data will show the focus of the review studies along with discussion of the techniques. The effectiveness is also reviewed from the number of references being used by the review studies. 


\begin{tabular}{|c|c|c|c|c|}
\hline $\begin{array}{l}\text { Ilakkiya \& Raviraj } \\
\text { [52] }\end{array}$ & $\begin{array}{l}\text { Automatic diagnosis of } \\
\text { tuberculosis }\end{array}$ & i) feature extraction, ii) classification & 14 & 6 \\
\hline Naing \& Hike [53] & $\begin{array}{l}\text { Automatic diagnosis of } \\
\text { tuberculosis }\end{array}$ & $\begin{array}{l}\text { i) SVM technique, ii) Decision Tree } \\
\text { iii) PCA, iv) Fuzzy ART Neural }\end{array}$ & 59 & 16 \\
\hline Jaeger et al. [54] & $\begin{array}{l}\text { Automatic diagnosis of } \\
\text { tuberculosis }\end{array}$ & i) Graph cut, ii) Feature extraction & 75 & 20 \\
\hline $\begin{array}{l}\text { Balagangadhar } \\
\text { [55] }\end{array}$ & Lung Tumor detection & i) Graph cut & 7 & 3 \\
\hline Joshi [56] & Segmentation of lung & $\begin{array}{l}\text { i) region growing, ii) 3D histogram, iii) } \\
\text { watershed transformation, iv) pixel } \\
\text { classification, v) deformable model, vi) } \\
\text { graph cut method, }\end{array}$ & 9 & 6 \\
\hline
\end{tabular}

\section{ABOUT EXISTING DATABASE SYSTEM}

At present, there is multiple resource of database explicitly required for carrying out analysis of chest radiographs. The brief discussion of the datasets based on its frequency of usage is discussed below:

\subsection{JSRT Database}

A JSRT standard for Japanese Society of Radiological Technology and it consists of 247 chest radiographs of $2048 \mathrm{x}$ 2048 pixel resolution. The database also consists of 100 malignant and 54 benign test images [57].

\subsection{Shenzhen Database}

This dataset is build from 3 hospitals from Shenzhen in China. It consists of 662 images of tuberculosis with $1130 \times 3001$ pixel resolution [58].

\subsection{Montgomery Database}

This database is build from the healthcare services from Montgomery in USA. It consists of a cumulative of 138 images of 4020 x 4892 pixel resolution. The database mainly consists of Radiological Images of patient suffering from tuberculosis [59].

\subsection{Indiana database}

It is one of the biggest databases that consist of 3996 radiological images of $1024 \times 4248$ pixel resolution. The database is mainly focused on tuberculosis disease with elaborated clinical reports of the disease [60].

\subsection{Indian database}

This dataset has 397 chest radiographs of 2446 x 2010 pixel resolution collected from hospitals in India. The images are quite challenging with various deformation of lungs, solid silhouette effect, and skewed image [61].

\subsection{SCR Database}

This database is mainly meant for performing segmentation of the chest radiographs. Basically, this dataset is derived from JSRT dataset by isolating the radiological images required for segmentation [62].

\subsection{VIA Group Public database}

It consists of more than 100 cases of Chest CT in DICOM format. The database is also accompanied by elaborated discussion of the clinical summary by the radiologist [63].

\section{RESEARCH METHODOLOGY}

Medical image processing has always posses a greater deal of challenges to find the most satisfactory solutions to the complex problems. Till the prior sections of the manuscript, various techniques of diagnosis of the chest radiographs are discussed. The discussion of prior literature is done with respect of problem identification, techniques used, performance observed, and limitations accompanied by it. In a nutshell, every research work discussed in this paper does have certain potential accomplishment as well as limitations. However, that shouldn't be bigger scale problems as every other research too has certain limitation. However, it is essential to understand some of the problems that do have existed in past and inspite of rigorous attempts, the problem is still unsolved. Therefore, we are more interested to understand such unsolved problems rather than discussion limitations. Hence, the identified research gaps explored in our investigation process are as follows:

\subsection{Only Focused on Similar Clinical Aspect}

As per our clinical review, the meaning of chest radiograph basically pertains to radiological investigation of thoracic cavity, where there are various organs e.g. rib cage, lung, heart, diaphragm, etc. However, majority of the study existed till date has not studied about heart and maximum focus was given to lung imaging. Even if we consider that lung to be clinically important, it shouldn't be overlooked that various forms of heart diseases are also screen through chest radiograph e.g. Doppler scan, MRI, PET scan etc. Another observation from the existing study is the majority of the existing system is focused on tuberculosis as a disease to be detected or classified from chest radiograph. Whereas less significant amount of work is focused on other critical diseases in lung. The proportion of the work on tuberculosis is very higher than amount of the research work done on lung cancer or pneumonia or internal hemorrhage etc.

\subsection{New Comparative Analysis}

Existing studies were found to discuss the outcomes with respect to visual outcomes and numerical outcomes. The outcomes were mainly seen to be evaluated with the performance parameters defined by the researchers on different database system. Although, such forms of analysis claims the robustness of the presented technique, but it doesn't showcase that it is the only best technique. Hence, researchers are required to compare the outcome of their study with some other significant work done by researcher on same problem. Therefore, comparative analysis assists to scale the effectiveness of the technique, which was very few to found in existing study. 


\subsection{Less Focus on Disease Classification}

The existing system of disease detection from the chest radiographs just results in precise segmentation process. In a nutshell, segmentation technique is highly emphasized in existing system. However, the segmentation technique is not found with enhanced classification system. Hence, we have also explored the implication of data mining technique, neural network technique, and support vector technique in order to mitigate the problems of classification. However, there are some of the major contradictions in this that doesn't make the existing system much applicable for classification viz.

\subsection{No Significant Work on Enhancement}

It is highly essential that every radiograph images should be preprocessed in order to retain maximum useful information required in next steps of processing. Chest radiographs are in various formats, types and colors. Hence, it is required to implement a technique to retain maximum resolution of the input image.

\subsection{Expensive Machine Learning Process}

In existing system, there are some work on chest radiograph towards disease classification done using data mining, neural network, and support vector machine. However, there are some issues observed in existing implementation e.g. i) no discussion on number of training required to get the elite outcome, ii) no illustration of validity of the condition set for identification of diseases in terms of preciseness, iii) training and learning process usually takes time of bigger size of medical image in DICOM format and its accuracy of disease detection and classification have higher dependency on size of trained data and hence not reliable, iv) implication of supervised technique e.g. SVM is more concern for enhancing the attributes of optimization to fit into the framework being selected. However, such approach is highly sensitive to over-fitting. v) The feature extraction process is not much emphasized in this process. There are various type of feature extraction algorithms, but none of the existing systems are found to emphasized on advanced process of feature extraction using more better version of visual descriptors e.g. color layout descriptor or edge histogram descriptor.

\subsection{Issues in Shape-based methods}

The existing techniques have also witnessed a shape-based technique (e.g. active contours) as an adopted mechanism of disease detection and classification from chest radiographs. The critical issues with such approaches are that such technique can lead to local minima over chest radiographs owing to potential edges of rib cage and maximized contrast. Shape-based method also heavily relies on approximating the accuracy factor, which is another trade-off.

\subsection{Less focus on Algorithm Complexity}

Automatic detection as well diagnosis of the abnormalities and diseases pertaining to the chest-radiograph is a complex process owing to involvement of various subtask e.g. pre-processing, feature extraction, and classification of the sophisticated formats (e.g. DICOM). Hence, the algorithms to perform such task will also require to be highly cost efficient with respect to time and space complexity. Till date, none of the existing techniques have any evidence of time and space complexity compliance.

\section{CONCLUSION}

Chest radiographs are one of the essential factors based on which the diagnosis of the chest disease is being made. Hence, the chest radiograph should have potential clinical information, free from any errors, should have multi-resolution quality for precise diagnosis process. If the detection of abnormality is carried out perfectly, than working on classification will not be much difficult to achieve. This paper has presented a review of existing chest radiographs and the existing tools used in this process. Right from 2001, there are many review studies being done till date related to chest-radiographs. This paper makes the difference by elaborating the studies with respect to limitations and exploration of research gap in this area.

The discussion shows that present techniques e.g. ultrasound, CT scan, PET scan, MRI etc are quite capable of collecting the significant information for diagnosis of the disease. Although there is nothing wrong or massive issues in this conventional process that we have witnessed in healthcare society from more than last 10 years, but there could be more improvement. A proper treatment could be only carried out if the disease position, criticality, and stages could be explored with high precision. Such phenomenon is extremely essential in treating cancer patient. India has some of the good chain of hospitals with highly skilled and competent doctors. Although the bigger groups of hospitals adopt advanced technology, but still it fails to cater up the emergence requirement of patient owing to manual processing of the data. This paper has also discussed that it is quite a challenging task for the radiological department to generate the clinical summary of patients ranging in hundreds per day. Therefore, there is an emergence requirement of an automated system to bridge this gap. Our investigation has also shown that existing researchers have introduced various techniques of detection as well as classification of disease and abnormalities from chest radiographs. The studies done most recently have advantages as well as limitations too, which is clearly discussed in the paper. The exploration of research gap is made after reviewing all the significant literatures.

Our future work direction will be towards mitigating such issues. We have noticed that very few works is also focused on image pre-processing. As majority of the literatures have adopted standard dataset, hence may be the existing researchers didn't emphasized on realizing robust preprocessing. For us preprocessing doesn't only mean removal of noise or other redundancies, it also means making the input image suitable for subjecting it to sophisticated forms of analysis. Hence, we are looking forward to carry out enhancement of chest radiograph resolution for superior patterns of capturing the clinical data. Our next direction of work will be towards investing effective disease detection and classification methods.

\section{REFERENCES}

[1] Teramoto, A., and Fujita, H.2013. Fast lung nodule detection in chest CT images using cylindrical noduleenhancement filter. International journal of computer assisted radiology and surgery, Vol. 8, No. 2, pp.193-205

[2] Hung, W., and Sarlis, N.J.2002. Current controversies in the management of pediatric patients with welldifferentiated nonmedullary thyroid cancer: a review. Thyroid, Vol. 12, No. 8, pp.683-702

[3] Garrido, V.V., Sancho, J.F., Blasco, H., Gafas, A.d.P., Rodríguez, E.P., Panadero, F.R., Candeira, S.R.2006. Diagnosis and treatment of pleural effusion. Archivos de Bronconeumología ((English Edition)), Vol. 42, No. 7, pp. 349-372

[4] Vakil, N.Z., Kahrilas, S. V. V., Dent, P., and Jones, R.2006. The Montreal definition and classification of 
gastro esophageal reflux disease: a global evidence-based consensus", The American journal of gastroenterology, Vol. 101, No. 8, pp.1900-1920

[5] Ginneken, B.V., Katsuragawa, S., Romeny, B. M. T. H., and Viergever, M.2002. Automatic detection of abnormalities in chest radiographs using local texture analysis. Medical Imaging, IEEE Transactions, Vol. 21, No. 2, pp.139-149

[6] Fanzou, G. N., Ninga, W., Cindy, N., Siewe, F., Xudong, L., Dea, X.2008. A case study of image retrieval on lung cancer chest X-ray pictures. In Signal Processing, ICSP, 9th International Conference, pp. 924-927

[7] Ohm, J-R., Cieplinski, L., Kim, H Jun., S Krishnamachari, B. S. Manjunath, Dean S. Messing, and A Yamada. The MPEG-7 color descriptors. IEEE Transactions on Circuits and Systems for Video Technology, 2001.

[8] Le, K.2010. Chest X-ray analysis for an active distributed E-health system with computer-aided diagnosis. Computer Sciences and Convergence Information Technology, 5th International Conference, pp. 727-732

[9] Sharma, D., and Jindal, G.2011. Identifying lung cancer using image processing techniques. In International Conference on Computational Techniques and Artificial Intelligence, pp. 115-120

[10] Lee, J-S., Wang, J-W., Wu, H-H., and Yuan, M-Z.2012. A nonparametric-based rib suppression method for chest radiographs. Computers \& Mathematics with Applications, Vol. 64, No. 5, pp. 1390-1399

[11] Tarambale, M.R., and Lingayat, N.S.2012. Soft Tool Developement For Characterization Of Lung Nodule From Chest X-Ray image. International Journal of Image Processing and Vision, Vol. 2, Issue.1

[12] Lingayat, N. S., and Tarambale, M.R.2013. A computer based feature extraction of lung Nodule in chest x-ray image. International Journal of Bioscience, Biochemistry and Bioinformatics, Vol.3, No. 6, PP 624-629

[13] Tarambale1, M. R., and Lingayat, N..2013. Spatial Domain Enhancement Techniques for Detection of Lung Tumor from Chest X-Ray Image", DR. Babasaheb Ambedkar Technological University's Institute of Petrochemical Engineering, Vol 2, Issue 8, pp 276-285

[14] Leibstein, J. M., and Nel, A. L.2006. Detecting tuberculosis in chest radiographs using image processing techniques. University of Johannesburg

[15] Belhaouair, S. B., and Kuleev, R. F.2014. On a New Approach to the Automated Detection of Thoracic Organs Diseases Using the Spot Feature in the Analysis of Digital X-Ray Images. Applied Mathematical Sciences, Vol. 8, No. 164, pp. 8171-8177

[16] Antani, S.2015. Automated Detection of Lung Diseases in Chest X-Rays.U.S. National Library of Medicine

[17] Yue, Z., and Goshtasby, A.1995. Automatic Detection Of Rib Borders In Chest Radiographs. IEEE Transactions on Medical Imaging, Vol 14, No. 3, pp. 525-536

[18] Matthew, B., L. S. Wilson, B.D. Doust, R.W.Gill, and Ch.Sun.1998. Knowledge-based method for segmentation and analysis of lung boundaries in chest X-ray images. Computerized medical imaging and graphics, Vol 6, pp. 463-477

[19] Iakovidis, Dimitris, K., and Papamichalis, G.2008. Automatic segmentation of the lung fields in portable chest radiographs based on Bézier interpolation of salient control points. In Imaging systems and techniques.IEEE International Workshop, pp. 82-87

[20] Hassen, D B., Taleb, H., Yaakoub, I.B., and Mnif, N.2011. A Fuzzy Approach to Chest Radiography Segmentation involving Spatial Relations. IJCA Special Issue on Novel Aspects of Digital Imaging Applications, pp 40-47

[21] Bandyopadhyay. 2012. A Method for Lung Boundary Detection. International Journal of Information, Vol. No. 2

[22] Sema, C., Jaeger, S., Palaniappan, K., Musco, J.P., Singh, R.K., Xue, Z., Karargyris, A., Antani, S., Thoma, G., and McDonald, C.J.2014. Lung segmentation in chest radiographs using anatomical atlases with nonrigid registration. Medical Imaging, IEEE Transactions, Vol.2, pp 577-590

[23] Devi, R., and Viveka, T .2015. Efficient Automatic Oriented Lung Boundary detection and Screening of Tuberculosis using Chest Radiographs", Journal of Network Communications and Emerging Technologies, Vol 2, Issue.1

[24] Ahmad, W. S. H. M. W., Zaki, W. M. D. W., and Faizal, M., Fauzi, A.2015. Lung segmentation on standard and mobile chest radiographs using oriented Gaussian derivatives filter. Wan Ahmad et al. Bio Medical Engineering OnLine, pp. 14:20

[25] Kaur, R., and Ada.2014. A Study of Detection of Lung Cancer Using Data Mining Classification Techniques", International Journal of Advanced Research in Computer Science and Software Engineering, pp. 131-134

[26] Rajan, J. R., and Prakash, J. J.2013. Early Diagnosis of Lung Cancer using a Mining Tool. In National Conference on Architecture, Software systems and Green computing

[27] Suzuki, K.., Shiraishi, J., Abe, H., MacMahon, H., and Doi, K.2005. False-positive reduction in computer-aided diagnostic scheme for detecting nodules in chest radiographs by means of massive training artificial neural network. Academic Radiology. Vol 12, No. 2, pp. 191-201

[28] Gomathi, M., and Thangaraj, P.2010. Lung nodule detection using a neural classifier. IACSIT International Journal of Engineering and Technology, Vol 2, No. 3, pp.291-295

[29] Udeshani, K.A.G., Meegama, R.G.N., \& Fernando, T.G.I.2011. Statistical feature-based neural network approach for the detection of lung cancer in chest $\mathrm{x}$-ray images. International Journal of Image Processing, Vol 5 , No. 4, pp.425-434

[30] Patil, S.A., and kuchanur, M. B.2012. Lung cancer classification using image processing. International Journal of Engineering and Innovative Technology, Vol 2, No. 3 .

[31] Karthikeyan, C., Ramadoss, B., and Baskar, S.2012. Segmentation algorithm for CT images using morphological operation and artificial neural network. International Journal of Signal Processing, Image 
Processing and Pattern Recognition, Vol 5, No. 2, pp. 115122

[32] Kumar, V., and Saini, A.2013. Detection system for lung cancer based on neural network: X-Ray validation performance. International Journal of Enhanced Research in Management \& Computer Applications, Vol. 2, Issue.9, pp. $40-47$

[33] Ramalho, G. L. B., Filho, P. P. R. Medeiros, F.N.S., Cortez, P.C.2014. Lung disease detection using feature extraction and extreme learning machine. Revista Brasileira de Engenharia Biomédica, Vol 30, No. 3, pp. 207-214

[34] Atsushi, T., and Fujita, H.2013. Fast lung nodule detection in chest CT images using cylindrical nodule-enhancement filter. International journal of computer assisted radiology and surgery, Vol. 2, pp.193-205

[35] Aarthy, K. P., and Ragupathy, U. S.2012. Detection of lung nodule using multiscale wavelets and support vector machine. International Journal of Soft Computing and Engineering (IJSCE), Vol. 2, No. 3

[36] Gomathi, M.2012. An effective classification of benign and malignant nodules using support vector machine. Journal of Global Research in Computer Science, Vol.7, pp.6-9

[37] Tidke, S.P., Chakkarwar, V.A.2012. Classification of Lung Tumor Using SVM. International Journal Of Computational Engineering Research, Vol. 2 , pp.12541257

[38] Sivakumar, S., and Chandrasekar, C.2013. Lung nodule detection using fuzzy clustering and support vector machines. International Journal of Engineering and Technology, Vol. no. 1, page no. 179-185, 2013.

[39] Parveen, S. Shaik, and Kavitha, C.2014. Classification of Lung Cancer Nodules using SVM Kernels. International Journal of Computer Applications, Vol. 95, pp.25

[40] Nivetha, P., Manickavasagam, R.2014. Lung Cancer Detection at Early Stage Using PET/CT Imaging Technique. International Journal of Innovative Research in Computer and Communication Engineering, Vol. 2, pp. 3358-3363

[41] Gindi, A., Amal, M., Attiatalla, T.A., and Sami, M.M.2014. A Comparative Study for Comparing Two Feature Extraction Methods and Two Classifiers in Classification of Earlystage Lung Cancer Diagnosis of chest x-ray images. Journal of American Science, Vol.10, pp. $13-22$

[42] Kaur, G., and Singh, H.2014. Lung Cancer Detection Using BPNN and SVM. International Journal of Latest Scientific Research and Technology, Vol.1(2), pp. 95-98

[43] Savitha, S. K., Aprameya, K.S., Pais A.R.2014. An efficient learning based algorithm for lung boundary detection for chest x-ray Images. International Journal of Emerging Trends \& Technology in Computer Science, Vol.3, Issue.4

[44] Xiang, W., D. Sontag, and F.Wang. 2014. Unsupervised learning of disease progression models. Proceedings of the 20th ACM SIGKDD international conference ,Knowledge discovery and data mining, pp. 85-94
[45] Gajdhane, A.Vijay, and Deshpande, L. M.2014. Detection of Lung Cancer Stages on CT scans Images by Using Various Image Processing Techniques. Journal of Computer Engineering (IOSR-JCE), Vol. 16, Issue.5, pp. 28-35

[46] Vivek, P.J., Swathika, S.R.2015. Accurate TB manifestation using multi class SVM classifier. International Advanced Research Journal in Science, Engineering and Technology, Vol. 2

[47] Ginneken, B. V., Romeny, B. M. H., and Viergever, M. A.2001. Computer-aided diagnosis in chest radiography: a survey. Medical Imaging, IEEE Transactions, Vol 20, No. 12 , pp. $1228-1241$

[48] Varshney, L. R.2002. Abdominal organ segmentation in CT scan images: a survey. Electrical and Computer Engineering, Cornell

[49] Bodhey, H., and Sable, G. S.2013. Adaptive Segmentation of the Pulmonary Lobes and Tumor Identification from Chest CT Scan Images. International Journal of Advanced Research in Computer and Communication Engineering, Vol. 2, Issue. 10

[50] Ginneken, V., Philipsen, R. H., Hogeweg, L., Maduskar, P., Melendez, J. C., Sánchez, C. I., Maane, R., Alorse, B.D., Alessandro, U., and Adetifa, I.M.2011. Automated Scoring of Chest Radiographs for Tuberculosis Prevalence Surveys: A Combined Approach. Medical Research Council Unit-Gambia

[51] Jaeger, S., Karargyris, A., Candemir, S., Siegelman, J., Folio, L., Antani, S., and Thoma, G.2013. Automatic screening for tuberculosis in chest radiographs: a survey. Quant Imaging Med Surg, Vol 3, No.2,pp.89-99

[52] Ilakkiya, V. N., and Raj, P.R. 2014. A Survey on Inherent Selection of Tuberculosis using Chest Radiographs", IJAICT ,Vol.1, Issue. 6

[53] Naing, W.Y.N., and Htike, Z.Z. 2014. Advances in automatic -tuberculosis detection in chest X-Ray Images. International Journal (SIPIJ) ,Vol.5, No.6

[54] Jaeger, S., Karargyris, A., Candemir, S., Folio, L., Siegelman, J., Callaghan, F., Xue, Z., Palaniappan, K., Singh, R. K., Antani, S., Thoma, G., Wang, Y. X., Lu, P. X., and McDonald, C. J.2014. Automatic tuberculosis screening using chest radiographs.Medical Imaging, IEEE Transactions, Vol 33, No. 2, pp.233-245

[55] Balagangadhar, Bottu, and Srilatha, K.2015. A Survey on PET-CT Lung Tumor Delineation. Middle-East Journal of Scientific Research, Vol. 23, pp. 3, 2015.

[56] Joshi, M.L., and Nalgirkar, P.P.2015. A Survey of Lung Segmentation Techniques. International Journal of Advanced Research in Computer Science and Software Engineering, Vol.5, pp.914

[57] Digital Image Database. (11th, July 2015). Retrieved from http://www.apastyle.org/learn/quick-guide-onreferences.aspx

[58] Antani, S.2015. Automated Detection of Lung Diseases in Chest X-Rays. A Report to the Board of Scientific Counselors 
[59] Montgomery College Libraries. (11th, July 2015).http://cms.montgomerycollege.edu/libraries/subject. html

[60] Indian Department of Correction. (11th, July 2015). http://www.in.gov/apps/indcorrection/ofs/ofs

[61] Dhandra, B.V., Malemath, V. S., Mallikarjun, H., and Mallikarjun, H. Hegadi, R.2006. Skew detection in Binary image documents based on Image Dilation and Region labeling Approach. In Pattern Recognition, ICPR. 18th International Conference, Vol. 2, pp. 954-957

[62] SCR database: Segmentation in Chest Radiographs. (11th, July 2015). http://www.isi.uu.nl/Research/Databases/SCR/

[63] Welcome to the VIA/I-ELCAP Public Access Research Database. (11th, July 2015). http://www.via.cornell.edu/lungdb.html 